against slavery rested, were gendered.

That said, Rediker's The Amistad Rebellion convincingly establishes the crucial role played by the African agents of an unprecedented historical victory for slaves and anti-slavery campaigners. It is a welcome addition to literature on slave agency and resistance, kinship, abolitionism, conditions on slave ships, Mende History, Atlantic World History, art history, slavery and labour history more broadly. This well-written, well-researched book successfully and rightly puts Africans at the centre of the Amistad rebellion. It is exceptionally illustrated with maps and images, and contains much of value for both specialists and the general public.

Karlee Anne Sapoznik

York University

\title{
Peter Boag, Re-Dressing America's Frontier Past. (Berkley: University of California Press, 2011).
}

The American western frontier is typically remembered as a hypermasculine space personified through the cultural images of Buffalo Bill, Davey Crocket, and Wyatt Earp. Peter Boag, however, challenges this interpretation in his new book Re-Dressing America's Frontier Past. Through an in-depth analysis of newspaper articles, correspondence, medical records, and popular fiction Boag argues that cross-dressers were a part of everyday life on the American frontier between 1850 and 1920. At the centre of Boag's analysis is the question: "how and why did such a large group of people so visible and so much a part of daily life in the nineteenth century West become so forgotten that their rediscovery was such an unexpected thing?” (2). In order to answer this question, Boag divides his study into two parts. The first, attempts to uncover the existence of crossdressers, both male-to-female and female-to-male, in the West, and analyze the realities of their daily lives, how they understood their own gender and sexual identities, and how they interacted with the larger community (8). The second looks at the heteronormalization of the western frontier, which took place in the early twentieth century and was directly related to the development of the modern gender and sexual system. Boag argues that the closing of the frontier coincided with the creation of the hetero and homosexual binary.

In the case of female-to-male cross dressers on the American frontier the creation of the progressive narrative led to their absence from our historical and cultural memory. Boag demonstrates that the progressive narrative has allowed both historians and society at large to accept the female-to-male cross dresser as a non-transgressive figure on the western frontier (19). The progressive narrative articulates that women dressed as men in order to gain male 
employment opportunities. In this light, female-to-male cross dressers can be understood historically without actually challenging modern gender and sexual norms. Boag, however, challenges this interpretation by providing other reasons for female-to-male cross-dressing. For example, gender inversion, desire to be the other sex, safe travel, and disguising oneself after breaking the law were all reasons for cross-dressing provided by women in the late nineteenth and early twentieth century. Boag argues that female-to-male cross dressers were accepted and integrated into society because they reinforced the masculine identity of the western frontier. Newspaper articles and popular fiction, such as the story of Calamity Janet, normalized the behaviour of the female-to-male cross dresser "by explaining these behaviors as merely due to a westering process" (194). According to Boag female-to-male cross dressing was an accepted part of frontier life into the twentieth century because it did not challenge traditional gender and sexual norms.

Although never quite as tolerated as the female-to-male cross dresser the male-to-female cross dresser was present on the western frontier. Boag, for instance, argues that female impersonators were a common feature in western stage shows. He also demonstrates that many men took on the dress of women in order to disguise themselves after committing a crime. In both of these instances male-to-female cross dressing was mildly accepted because it did not directly challenge the modern sex/gender system despite the fact that some of these individuals were engaged in same-sex relationships. Another factor that contributed to the protection of the white, masculine, heteronormative ideal on the western frontier was "racializing the cross-dresser and feminizing the nonAnglo male" (194). In other words, those who cross dressed were 'othered' based on racial transgressions and not gender non-conformity. In this way maleto-female cross dressers were present and at times tolerated on the western frontier because they existed outside of the hegemonic norm. According to Boag it was not until the turn of the twentieth century and the development of sexology that cross dressers were erased from the history and culture of western frontier life.

Boag argues that modern sexologists at the turn of the twentieth century connected gender and sexual inversion to urban problems such as neuosethenia and degeneration (178). Cross dressing was one characteristic of a gender invert and thus was increasingly considered an urban phenomenon confined to the north eastern United States. The rural frontier was romanticized and actually considered a solution to the problems and vices of modern urbanization.

Sexologists, therefore, positioned sexual and gender inversion as something that existed outside of rural, frontier life. Sexological research, according to Boag, contributed to the heteronormalization of the frontier and subsequently erased the cross dresser from the collective memory.

Peter Boag's well-written and researched monograph challenges tradi- 